\title{
Seismic Performance of Ancient Masonry Structures in Korea Rediscovered in 2016 M 5.8 Gyeongju Earthquake
}

\author{
Heon-Joon Park ${ }^{1, * \mathbb{D}}$, Jeong-Gon $\mathrm{Ha}^{2}$, Se-Hyun Kim ${ }^{3}$ and Sang-Sun Jo ${ }^{3, *}$ \\ 1 Ulsan National Institute of Science and Technology (UNIST), Ulsan 44919, Korea \\ 2 Korea Atomic Energy Research Institute (KAERI), Daejeon 34057, Korea; jgha@kaeri.re.kr \\ 3 National Research Institute of Cultural Heritage (NRICH), Daejeon 34122, Korea; ksehyun@korea.kr \\ * Correspondence: heonjoon@unist.ac.kr (H.-J.P.); ssjo@korea.kr (S.-S.J.); Tel.: +82-52-217-2850 (H.-J.P.); \\ $+82-42-860-9216$ (S.-S.J.)
}

Received: 30 January 2019; Accepted: 6 March 2019; Published: 14 March 2019

\begin{abstract}
The Gyeongju Historic Areas, which include the millennium-old capital of the Silla Kingdom, are located in the region most frequently affected by seismic events in the Korean peninsula. Despite the numerous earthquakes documented, most of the stone architectural heritage has retained their original forms. This study systematically reviews and categorises studies dealing with the seismic risk assessment of the architectural heritage of the historic areas. It applies research methodologies, such as the evaluation of the engineering characteristics of subsoil in architectural heritage sites, site-specific analysis of the ground motions in response to earthquake scenarios, geographic information system (GIS)-based seismic microzonation according to the geotechnical engineering parameters, reliability assessment of dynamic centrifuge model testing for stone masonry structures and evaluation of seismic behaviour of architectural heritage. The M 5.8 earthquake that hit Gyeongju on 12 September 2016 is analysed from an engineering point of view and the resulting damage to the stone architectural heritage is reported. The study focuses on Cheomseongdae, an astronomical observatory in Gyeongju, whose structural engineering received considerable attention since its seismic resistance was reported after the last earthquake. Dynamic centrifuge model tests applying the Gyeongju Earthquake motions are performed to prove that it is not a coincidence that Cheomseongdae, a masonry structure composed of nearly 400 stone members, survived numerous seismic events for over 1300 years. The structural characteristics of Cheomseongdae, such as the well-compacted filler materials in its lower part, rough inside wall in contrast to the smooth exterior, intersecting stone beams and interlocking headstones are proven to contribute to its overall seismic performance, demonstrating outstanding seismic design technology.
\end{abstract}

Keywords: Gyeongju Historic Areas; 2016 Gyeongju Earthquake; site characterisation; site-specific ground response analysis; stone architectural heritage; dynamic centrifuge test; Cheomseongdae; ancient seismic design technique

\section{Introduction}

Architectural heritage is a precious cultural asset that provides insight into a nation's historical background. As such, the current generation has the duty to preserve them well for future generations. Since architectural heritage is exposed to the external environment, measures should be taken to protect them from both natural and manmade disasters. Systematic approaches based on scientific and engineering applications should be adopted to protect them from natural disasters such as earthquakes. Unlike seismic performance and design assessments of general buildings, the main focus of seismic risk 
assessments for architectural heritage should be on the maintenance of their unique values, authenticity and engineering performance.

There are many interesting ways for geotechnical engineers to contribute to conservation issues for historic sites and monuments [1]. Geotechnical engineering also has a very important role to play because there are quite a number of historic sites and monuments affected by geotechnical risks of different types [2]. As all architectural heritages are standing on ground, the seismic risk assessments for architectural heritage can be initiated from geological and geotechnical approaches to understand the composition and the material property distribution of the beneath and surrounding ground, local site effect, and seismic zonation [3-6]. For the structural and architectural engineering perspective, the seismic behaviour of historic monument and architectural heritage composed of stone block or masonry structure have been evaluated analytically, numerically [7-11] and experimentally [12-15].

In Korea, the National Research Institute of Cultural Heritage [16] conducted a multidisciplinary research planning project on disaster prevention for architectural heritages. Detailed mid- and long-term research tasks were derived from this project, and various studies were conducted to develop an overarching cultural heritage disaster-prevention system. Among them, studies on seismic risk assessments were conducted on architectural heritage in historic cities from 2009 to 2012. In addition, a seismic risk assessment methodology for historic areas was proposed based on aspects of geotechnical earthquake engineering.

A seismic risk assessment for architectural heritage at a historical site begins with an understanding of the engineering characteristics of the subsoil and architectural structure. First, an investigation of the subsoil and seismic response analysis are performed at an architectural heritage site to predict the level of ground shaking for each earthquake scenario. Furthermore, an information system based on a geographic information system (GIS) for determining the geotechnical earthquake engineering parameters can be established to estimate the damage potential for each historic area. Architectural heritage has different structural forms, systems and load transfer characteristics. Hence, the seismic behaviour of each architectural heritage must be analysed using an empirical or analytical approach through experimental or numerical modelling. To improve the efficiency of such research, major architectural heritage, each representative of their specific epochs and styles, should be selected and their seismic behaviour characteristics should be evaluated.

In this research project, seismic risk assessments were carried out for the subsoils of historical sites in Gyeongju, Buyeo and Seoul in 2009, 2010 and 2011, respectively. A geotechnical earthquake engineering database of over 70 architectural heritage sites in these three historical cities was established by means of in situ tests [17]. This database served as the basis for setting up a GIS-based geotechnical earthquake engineering information system for Gyeongju and Buyeo [18]. Stone architectural heritage exhibits dynamic seismic behaviour due to the friction between the stone members. This behaviour can be evaluated through centrifuge testing using scaled-down models [19]. The three-story stone pagoda (Seokgatap (Shakamuni Stupa)) of Bulguksa Temple and the five-story stone pagoda of Jungnimsa Temple, which are representative of the architectural style of the time, were evaluated along with their seismic behaviours using multiple dynamic centrifuge tests with a shaking table [20]. The dynamic centrifuge tests were conducted for scaled models of Cheomseongdae, an astronomical observatory in Gyeongju that has unique structural features [21]. The results of this study were used in 2012 as basic data to establish an architectural heritage seismic performance and risk assessment method and to propose standards for seismic risk assessments.

The M 5.8 earthquake that hit Gyeongju on 12 September 2016 is analysed in this study from an engineering point of view and the related damages to the stone architectural heritage are reported with a focus on Cheomseongdae. Dynamic centrifuge model tests that apply the Gyeongju Earthquake motions are performed to prove that it is not a coincidence that Cheomseongdae, a masonry structure composed of nearly 400 stone members, survived numerous seismic events for over 1300 years. Based on the assessment of the damage to the stone architectural heritage and the results of earthquake 
monitoring and dynamic centrifuge model tests for Cheomseongdae, the efforts before and after the Gyeongju earthquake and its reliability are verified from an engineering viewpoint.

\section{Gyeongju Historic Areas and Cheomseongdae}

The Gyeongju Historic Areas, the millennium-old capital of the Silla Kingdom (57 B.C.-935 A.D.) and UNESCO World Heritage Sites, are the representative heritage areas, as they are the cradle and pivot of the development of Buddhism in the Korean peninsula. The vibrant Buddhist culture in the area resulted in the creation of numerous stone heritages such as pagodas, lanterns, bridges and revetments. Many of the existing stone heritage have structures that are seemingly susceptible to collapse under lateral loads such as those produced during earthquakes. However, despite the numerous earthquakes documented, most of the aforementioned architectural heritage remained intact for over a millennium.

The Gyeongju Historic Areas are adjacent to the Yangsan Fault, and many seismic events in this area have been documented. In Samguksagi (a historical record of the Three Kingdoms), there is a record of an earthquake in 779 that killed more than 100 people and is the largest documented estimation of casualties due to an earthquake. The scroll, whose deciphered content began to be released in 2007, was discovered in 1966 while dismantling the three-story stone pagoda in the Bulguksa Temple. It contains records of great damage to the Bulguksa Temple facilities and Seokgatap pagoda due to earthquakes in 1013 and 1036. The scroll also describes the entire process from dismantling to rebuilding of the Seokgatap pagoda.

Park et al. [18] summarised and systemised the pre-existing site investigation databases of 50 sites, the results of in situ experiments conducted at 32 architectural heritage sites in the Gyeongju area and the results of the site-specific ground response analyses for scenario earthquakes. Using these data and site-specific response analysis results, they generated a GIS-based visualisation of the bedrock depths, natural ground periods, peak ground accelerations and ground amplification ratios for an earthquake scenario. Gyeongju is located in a basin of plains and low hilly areas with settlements and paddies / fields surrounded by mountains, through which the Hyeongsan River flows. The river is fed by various tributaries, such as Bukcheon (north stream) and Namcheon (south stream). The ground here is predominantly composed of a gravelly alluvial soil layer below a 1-4 m-deep gravelly fill layer in which weathered soils, residual soils, weathered rocks and soft rock layers are locally distributed. The depth of the soft rocks varies greatly according to the drilling location and are distributed 8 to $50 \mathrm{~m}$ below the ground surface.

Located between the Bukcheon and Namcheon streams in the centre of the Gyeongju Historic Areas, Cheomseongdae (National Treasure 31) stands on a typical sedimentary basin terrain covered with a thick flood-induced alluvial deposit layer. Core samples taken from the subsoils near Cheomseongdae revealed a vertical soil profile $(1-16 \mathrm{~m})$ of sandy gravel and boulders. The depth-dependent stiffness distribution was derived from in situ down-hole and surface wave tests performed; these results were used to determine the seismic motions considering the site amplification factors. In other words, the surface motion at Cheomseongdae ground in each earthquake scenario was analysed. As a result, the ground around Cheomseongdae was found to incur a peak ground acceleration amplification of approximately 1.85 times.

The Cheomseongdae observatory was constructed during the reign of Queen Seondeok (632-646). Its original form survived over 1300 years of exposure to the natural and manmade disasters such as earthquakes. This stone masonry structure is comprised of nearly 400 stone members. Its materials and structure are maintained in their original state, and it is a monument of high artistic value with a mixture of harmoniously contrasting curves, straight lines, circles and squares.

Cheomseongdae's smoothly curved cylindrical main body consists of 27 layers of stone members piled up on a square stylobate and pedestal as shown in Figure 1 [21]. Two layers of interlocking headstones are placed on top of the main body. There is a small three-layer-high (13th to 15th layer) entrance or window facing south. The inside of the wall from the first to the 12th layer is densely 
packed with irregularly shaped and sized rubble and soil, whereas the inside is empty from the 13th layer onwards (Figure 1a). Unlike the smooth exterior of the main body, the interior is composed of roughly touching stone members up to the 18th layer (Figure 1b). The 19th layer comprises two stone beams with rectangular cross-sections that are placed in the east-west direction, piercing the cylindrical plane with their ends protruding. The 20th layer comprises two identically shaped stone beams placed in the north-south direction across the stone beams below (19th layer) without piercing the wall (Figure 1c). This structure is considered to enhance the frictional and adhesive forces between the members. The 21st-24th layers comprise stone members that are piled in the same manner as in the 12th-18th layers. The 25th and 26th layers show the same pattern as in the 19th and 20th layers, but in the opposite direction, i.e. with the two stone beams piercing the cylindrical plane in the north-south direction in the 25th layer and another two beams placed across them in the 26th layer. The 27th layer has a stone slab slanted to the east. The top part of Cheomseongdae is square. The 28th layer has two stone beams with quasi-square cross-sections that are placed in the east-west direction and another two identically shaped beams that are placed in the north-south direction inserted into the grooves made on the members underneath them. The same interlocking pattern is applied to the 29th layer with the reverse directions, i.e. the east-west members are inserted into the north-south members using a half-lap joint (Figure 1d).

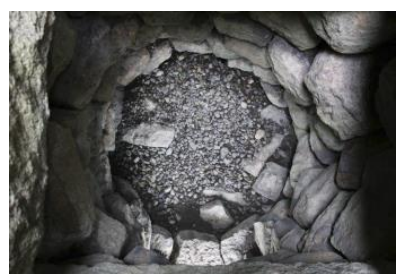

(a)

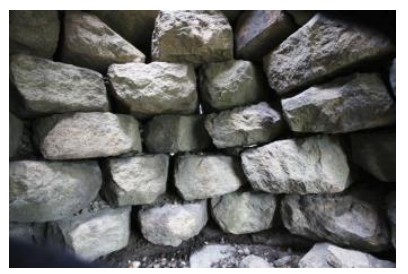

(b)

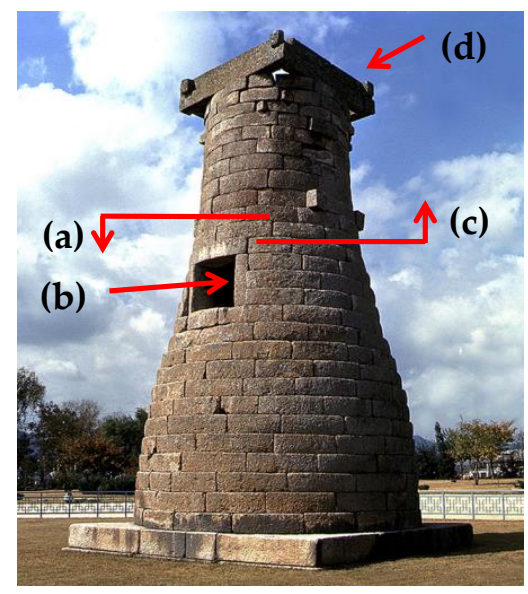

(b)

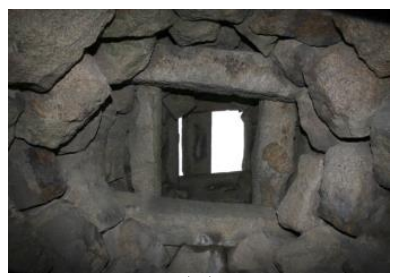

(c)

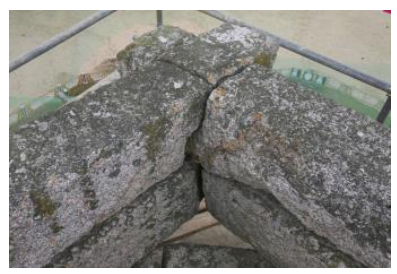

(d)

Figure 1. The photos of exterior and interior of Cheomseongdae: (a) Filler beneath the 13th layer; (b) Inner irregular-shaped stones; (c) Long-shaped horizontal tie stones of 19th, 20th, 25th and 26th layers; and (d) Grid of interlocking stones and half-lap joint [21].

In a previous study [21], dynamic centrifuge tests were performed on two Cheomseongdae models to compare their seismic responses. One model was an exact duplicate of the actual structure and the other was a duplicate without the interlocking headstones and intersecting stone beams. As a result, the roles of the interlocking headstones and stone beams in enhancing Cheomseongdae's seismic performance were verified. Additionally, the rough interior members in contrast to the smooth exterior, the densely packed filler materials in the space below the window, the shapes of the stone members from the 19th layer onward and the shape of the joints lead to the belief that the Cheomseongdae structure is resistant to dynamic lateral loading such as earthquakes. In the dynamic centrifuge model tests on the Cheomseongdae models, the headstones underwent lateral displacements of up to $1.46 \mathrm{~mm}$ from a $1 \mathrm{~s}$ earthquake excitation in a $15 \mathrm{~g}$ centrifugal gravitational field under a seismic wave similar to that in the Ofunato earthquake with a return period of 1000 years $(0.333 \mathrm{~g}$ of surface peak ground acceleration). By applying this result to the ground response analysis, a lateral displacement of $21.9 \mathrm{~mm}$ was estimated to occur under a $15 \mathrm{~s}$ earthquake excitation based on scaling factors from the dynamic centrifuge test. 


\section{Gyeongju Earthquake on 12 September 2016 and Damage to Architectural Heritage}

There are 75 records of seismic events from 64 to 932 when Gyeongju was the capital of the Silla Dynasty. The Korea Meteorological Administration set up an analogue seismic monitoring network in 1978 after the Hong Sung earthquake (M 5.0), and a nationwide digital seismic monitoring network in 1997 after the Gyeongju Earthquake (M 4.2). A total of 21 earthquakes were recorded in the Gyeongju area between 1978 and 2016 prior to the 2016 Gyeongju earthquake. On 12 September 2016, a M 5.1 foreshock hit a region $8.2 \mathrm{~km}$ south-south-west of Gyeongju at 19:44, followed by a M 5.8 earthquake at 20:32. It was the largest earthquake after the creation of the seismic observation network in Korea, and vibrations were felt in most parts of the country [22].

Despite being the largest-scale earthquake ever recorded in the Korean peninsula, the damage of the 9-12 Gyeongju Earthquake was not as extensive as expected because it lasted only 5-7 s, with an approximately 1-2 s strong motion duration, and mostly high-frequency components were observed. The majority of the damage was incurred by medium-high and low structures, stone fences and stone structures, including architectural heritage, which were more susceptible to the high-frequency components.

At the MKL station in Gyeongju Myeonggye-ri $\left(35.7322{ }^{\circ} \mathrm{N}, 129.2420{ }^{\circ} \mathrm{E}\right)$, the earthquake monitoring station with rock-outcrop condition closest to the epicentre (epicentral distance: $5.68 \mathrm{~km}$ ), the peak ground acceleration values measured within the time domain sampled at $100 \mathrm{~Hz}$ were $0.346 \mathrm{~g}$ for the E-W component and $0.275 \mathrm{~g}$ for the N-S component. At USN station in Ulsan Bokan-ri $\left(35.7024^{\circ} \mathrm{N}, 129.1232^{\circ} \mathrm{E}\right)$, the earthquake monitoring station with soil condition closest to the epicentre, the measured peak acceleration was $0.400 \mathrm{~g}$ for the E-W component and $0.430 \mathrm{~g}$ for the N-S component.

The 9-12 Gyeongju Earthquake damaged 52 designated cultural heritage sites. Bulguksa Temple suffered considerable damage. For example, roof tiles fells from the Main Buddha Hall (Daewoongjeon), walls in the west corridor were cracked, the fence of Guanyeumheon was destroyed and the banister joints in Dabotap Pagoda were displaced. In Cheomseongdae, the interlocking headstones moved and were partially displaced. Figure 2 illustrates the typical damages to the stone pagoda caused by the 9-12 Gyeongju Earthquake. Table 1 provides an overview of the seismic damage to the stone pagodas due to the Gyeongju Earthquake (modified from Kim et al. [23]). Most of the damaged stone pagodas have three stories and a main body composed of massive stones. Various parts of the pagodas suffered damage including the base, main body and steeple. Serious structural damage was not observed, and most damage included cracking, separation and displacement of non-structural members.

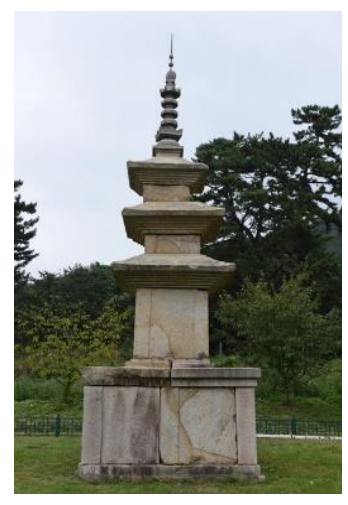

(a)

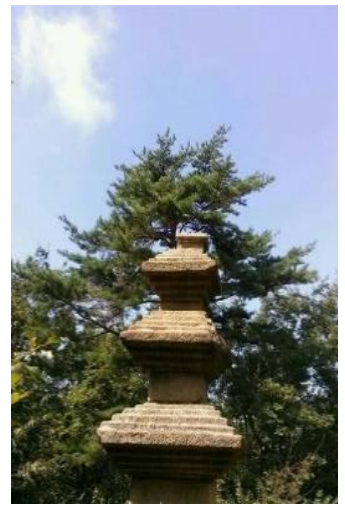

(b)

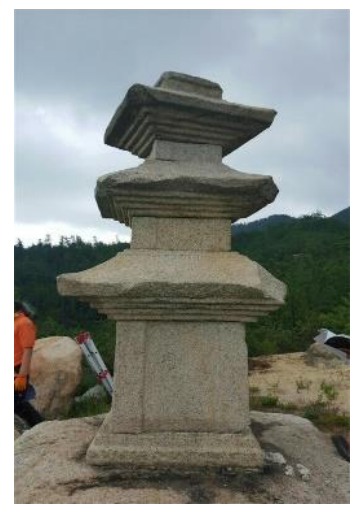

(c)

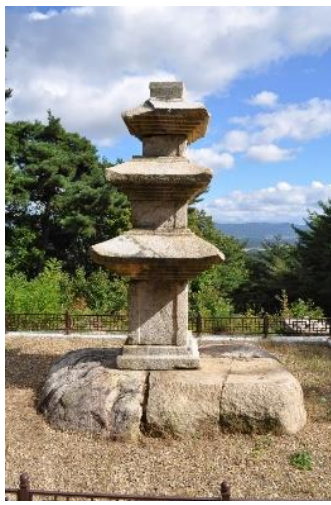

(d)

Figure 2. Typical damages to stone pagoda caused by 9-12 Gyeongju Earthquake (Photo by NRICH): (a) Separated third-story body stone, three-story Stone Pagoda at Cheollyongsa Temple Site in Namsan Mountain; (b) Rotated stone member, displaced third-story body stone, three-story Stone Pagoda of Yongjanggye Jigok Valley in Namsan Mountain; (c) Rotated body and roof stones, three-story Stone Pagoda of Bipagok Valley in Namsan Mountain; and (d) Displaced third-story body and roof stones, rhree-story Stone Pagoda of Jiamgok Valley in Namsan Mountain. 
Table 1. Seismic damage incurred by stone pagodas due to the 9-12 Gyeongju Earthquake.

\begin{tabular}{|c|c|c|c|}
\hline Classification & Name of Cultural Heritage & Seismic Damage & Height $(\mathrm{m})$ \\
\hline National Treasure 20 & Dabotap Pagoda of Bulguksa Temple & Displaced banister joints & 10.3 \\
\hline National Treasure 30 & Stone Brick Pagoda of Bunhwangsa Temple & Cracked lower part & \\
\hline Treasure 168 & $\begin{array}{l}\text { East and West Three-story Stone Pagodas in } \\
\text { Cheongun-dong }\end{array}$ & $\begin{array}{l}\text { Destroyed steeples of the east and } \\
\text { west pagodas }\end{array}$ & $\begin{array}{l}\text { East } 6.73, \\
\text { West } 7.72\end{array}$ \\
\hline Treasure 678 & $\begin{array}{c}\text { East and West Three-story Stone Pagodas of } \\
\text { Unmunsa Temple }\end{array}$ & $\begin{array}{l}\text { Loosen east pagoda roof stone, tilted } \\
\text { west pagoda, cracked main body }\end{array}$ & \\
\hline Treasure 908 & Three-story Stone Pagoda in Yongmyeong-ri & Chipped upper end of main body & 5.6 \\
\hline Treasure 1188 (Figure 2a) & $\begin{array}{l}\text { Three-story Stone Pagoda at Cheollyongsa Temple } \\
\text { Site in Namsan Mountain }\end{array}$ & Separated third-story body stone & 7.16 \\
\hline Treasure 1429 & $\begin{array}{l}\text { East and West Three-story Stone Pagodas at } \\
\text { Wonwonsa Temple Site }\end{array}$ & Broken east pagoda roof stone & 6.04 \\
\hline Treasure 1867 & $\begin{array}{l}\text { Three-story Stone Pagoda at Changnimsa Temple } \\
\text { Site of Namsan Mountain }\end{array}$ & $\begin{array}{l}\text { Cracked base, separated main body, } \\
\text { partially broken roof stone }\end{array}$ & 7.0 \\
\hline $\begin{array}{l}\text { Treasure } 1935 \\
\text { (Figure 2b) }\end{array}$ & $\begin{array}{c}\text { Three-story Stone Pagoda of Yongjanggye Jigok } \\
\text { Valley in Namsan Mountain }\end{array}$ & $\begin{array}{l}\text { Rotated stone member, displaced } \\
\text { third-story body stone }\end{array}$ & \\
\hline Historic Site 311 & $\begin{array}{l}\text { Archaeological Area of Namsan Mountain } \\
\text { (Three-story Pagoda of Yeonbulsa Temple Site) }\end{array}$ & Loosened third-story body stone & 7.0 \\
\hline $\begin{array}{l}\text { Province-Designated Tangible } \\
\text { Cultural Heritage } 448 \\
\text { (Figure 2c) }\end{array}$ & $\begin{array}{c}\text { Three-story Stone Pagoda of Bipagok Valley in } \\
\text { Namsan Mountain }\end{array}$ & $\begin{array}{l}\text { Rotated body and roof stones } \\
\quad \text { (counter clockwise) }\end{array}$ & \\
\hline $\begin{array}{l}\text { Province-Designated Tangible } \\
\text { Cultural Heritage } 449 \\
\text { (Figure 2d) }\end{array}$ & $\begin{array}{l}\text { Three-story Stone Pagoda of Jiamgok Valley in } \\
\text { Namsan Mountain }\end{array}$ & $\begin{array}{l}\text { Displaced third-story body and } \\
\text { roof stones }\end{array}$ & \\
\hline
\end{tabular}

In the case of Cheomseongdae, continuous monitoring has been carried out since 2009 with regard to member separation and displacement, separation of interlocking headstones due to destroyed joints and tilting of the structure [24]. Before the earthquake, the centre axis of Cheomseongdae was tilted towards the north by $\sim 200 \mathrm{~mm}$, and the southeast and northwest corner of headstones had partially lost their original joint.

As predicted in the previous model tests [21], the seismic damage of Cheomseongdae during the Gyeongju Earthquake on 12 September 2016 was more intense in the upper part than in the lower part filled with filler materials, and the separation and detachment of the stone members in the upper part and the displacement of the southeast headstones was clearly visible. A precise analysis of the results of a 3D survey conducted immediately after the Gyeongju Earthquake showed that the upper headstones were twisted and rotated clockwise, as shown in Figure 3 [25].

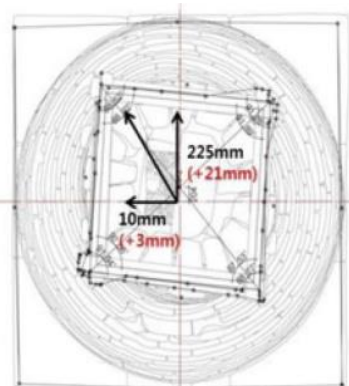

(a)

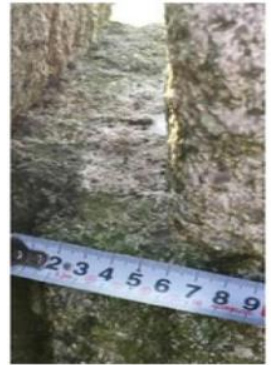

(b)

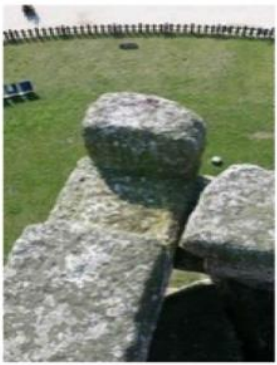

(c)

Figure 3. Displacement of Cheomseongdae headstones caused by the 9-12 Gyeongju Earthquake: (a) Displacement and rotation of headstones; (b) Displacement measurement of headstones; and (c) Separation of headstones on southeast corner.

The southern upper headstone moved $38 \mathrm{~mm}$ to the north after joint failure caused by the M4.6 aftershock on September 19, 2016. The overall behaviour of the structure was evaluated by analysing the extent of member separation and tilting. No damages were reported other than the cracking and separation of the upper headstone and separation of some stone members. 


\section{Dynamic Centrifuge Tests for Cheomseongdae Model}

As mentioned, a seismic performance assessment for architectural heritage sites begins with obtaining an understanding of the engineering characteristics of the subsoil and architectural structure. First, a site investigation and seismic response analysis are performed at an architectural heritage site to predict the level of ground shaking for each earthquake scenario. Seismic loading exerted on an architectural heritage triggers different seismic behaviours and performances depending on the structure type and style and the load transfer characteristics. Therefore, an empirical or analytical approach based on experimental or numerical modelling of each architectural heritage site is necessary to understand its seismic behaviour.

In the previous study [19], a dynamic centrifuge test was proposed to evaluate the seismic behaviour of stone block structures. If appropriate scaling factors are applied and the model material has the same density as the real structure, the seismic behaviour can be observed under the same stress conditions as reality. Based on the study, the dynamic centrifuge model test was proposed for seismic performance assessment to evaluate how the stone architectural heritage resists seismic loads and whether it can resist damage from future earthquakes [20]. Table 2 shows the scaling factors for the dynamic centrifuge model test.

Table 2. Scaling factors of dynamic centrifuge test for stone block and architectural heritage model.

\begin{tabular}{cc}
\hline Quantities & Scaling Factors (Prototype/Model) \\
\hline Displacement, Length & $\mathrm{N}$ \\
Acceleration, Gravity & $\mathrm{N}^{-1}$ \\
Mass & $\mathrm{N}^{3}$ \\
Density & 1 \\
Stress & 1 \\
Strain & 1 \\
Time (Dynamic) & $\mathrm{N}$ \\
\hline
\end{tabular}

The Cheomseongdae ground response was analysed based on an actual seismic waveform measured on 12 September 2016, at MKL station. Dynamic centrifuge model tests were performed on the Cheomseongdae model using the surface response obtained from the site-specific ground response analysis, which enabled Cheomseongdae's seismic performance to be re-assessed.

\subsection{Ground Response Analysis and Generation of Input Motion for Shaking Table}

The ground response for the Gyeongju Earthquake accelerograms measured at the MKL station was analysed using the shear-wave velocity profile and the modulus reduction and damping curve of each ground material at Cheomseongdae determined in a previous study [18]. The peak acceleration value of the E-W component measured at the MKL station was higher than that of the N-S component. The E-W component contained a higher proportion of high-frequency components whose frequency exceeded $25 \mathrm{~Hz}$ than the N-S component. Given that components with frequencies lower than $25 \mathrm{~Hz}$ are more important in ground engineering and structural engineering and considering the excitation frequency band of the shaking table, the N-S component of MKL was used in this study [26].

Figure 4 shows the results of the Cheomseongdae ground response analysis for the Ofunato Earthquake motion and the Gyeongju MKL (N-S component) motion. The waveforms of the latter had a shorter duration of strong motion than those of the former with a similar peak acceleration value. Based on a threshold acceleration of $0.05 \mathrm{~g}$, the bracketed durations $T_{d}$ were $11.35 \mathrm{~s}$ and $3.23 \mathrm{~s}$ for the Ofunato and Gyeongju earthquakes, respectively. Moreover, the Arias intensity $I_{a}$ values [27] used for a quantitative calculation of the duration of strong motion were 0.0335 and $0.0039 \mathrm{~m} / \mathrm{s}$ for the Ofunato and Gyeongju Earthquake motions, respectively. 


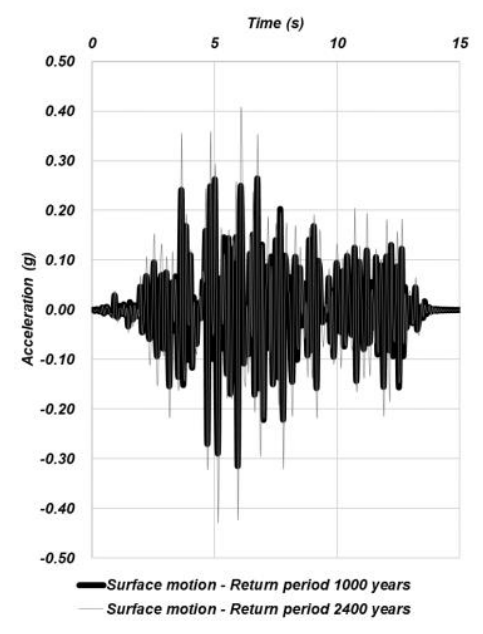

(a)

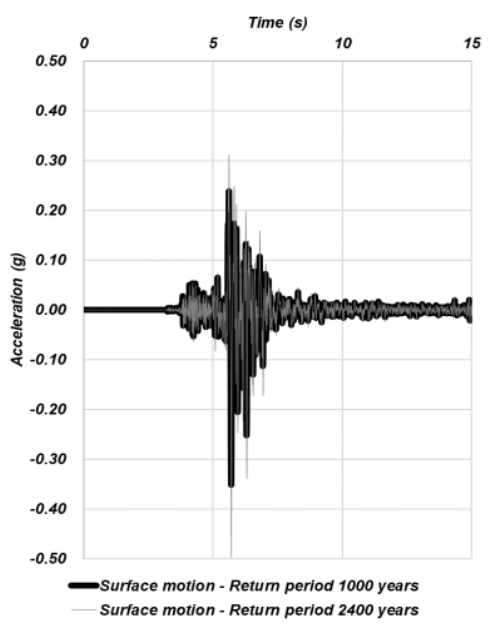

(b)

Figure 4. Ground response analysis for Cheomgeongdae site: (a) Ofunato earthquake motion; and (b) Gyeongju MKL motion.

The frequency range of the shaking table mounted on the centrifuge was $30-300 \mathrm{~Hz}$ for the scale model. Hence, the tests were performed at a centrifugal gravitational field of $15 \mathrm{~g}$ using a $2-20 \mathrm{~Hz}$ prototype-scale component. The time history from the ground response analysis results was converted using the bandpass filter of the $2-20 \mathrm{~Hz}$ component. As a result, the $T_{d}$ values of the input seismic wave used for actual testing were $11.15 \mathrm{~s}$ and $2.46 \mathrm{~s}$ for the Ofunato and Gyeongju Earthquake motions, respectively.

\subsection{Preparation of Cheomseongdae Models and Centrifuge Model Testing}

To analyse Cheomseongdae's seismic behaviour characteristics, 1/15-scale models were created, and dynamic centrifuge model testing was performed using a centrifuge device and shaking table from the KAIST Geo-Centrifuge Testing Center [28,29]. The scaling factors were considered by applying a $15 \mathrm{~g}$ centrifugal force vertically, which is 15 times the gravitational acceleration, to the $1 / 15$-scale Cheomseongdae model. Hwangdeung granite was used for the model members because its density and stiffness are closest to those of the material at Cheomseongdae. This enhances the plausibility of reproducing the actual seismic behaviour of Cheomseongdae.

All the stone members of the model were fabricated manually to produce models as accurately as possible. Cheomseongdae is composed of over 380 stone members, of which the long members of the 19th, 20th, 25th and 26th layers, and the two headstone layers were proven to contribute to bearing larger lateral loads. Shaking table tests were performed within centrifuge to compare the seismic behaviour of the Cheomseongdae models with and without the four headstones that are supposed to enhance the seismic performance, as shown in Figure 5. 


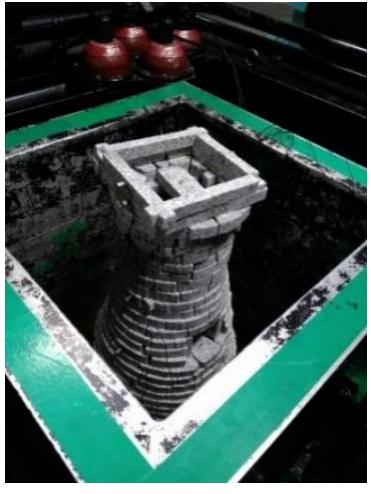

(a)

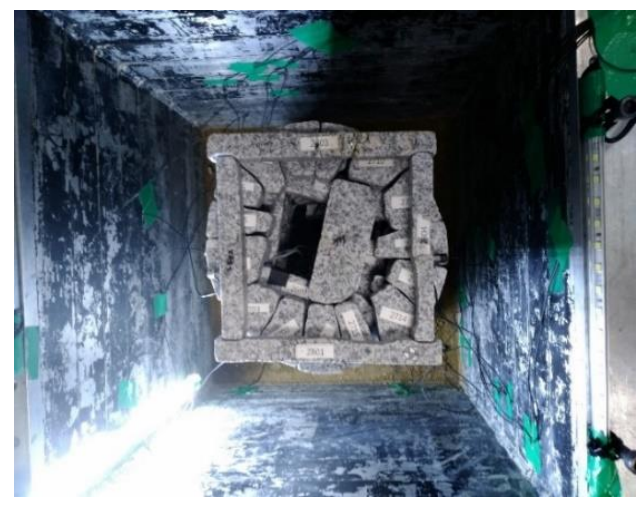

(b)

Figure 5. Cheomseongdae model: (a) Cheomseongdae model with headstones; and (b) Cheomseongdae model without headstones.

Accelerometers were installed at eight heights on the east side of the Cheomseongdae model, and the model was subjected to Gyeongju Earthquake motions in the east-west direction. The accelerometers were placed in the vibration shaker of the centrifuge model tester, Cheomseongdae base, 12th layer (on the filler surface), 13th layer (southern window above the filler), 19th layer (stone beam), 25th layer (stone beam), 26th layer (stone beam), 28th layer (lower headstone) and 29th layer (upper headstone). The 28th and 29th layers were used for the prototype model only. The Ofunato and Gyeongju Earthquake motions were applied during the tests, starting from a low acceleration that was gradually increased. For both Cheomseongdae models, seismic waves were applied six times per waveform. The acceleration results were processed after converting them into the actual Cheomseongdae prototype unit and taking the scale factor into account. These were used to explain the actual phenomena that may occur at Cheomseongdae during an earthquake, considering the scale factor for the $1 / 15$ scale and $15 \mathrm{~g}$ conditions with respect to size, duration and frequency.

\subsection{Acceleration Amplification With Height at Cheomseongdae}

Figure 6 shows the peak acceleration values measured at various heights for the two Cheomseongdae models (with and without headstones) exposed to Ofunato and Gyeongju Earthquake motions. Almost no acceleration amplification was measured in the lower parts under the window, i.e. the part packed with filler materials, and different acceleration values were measured in the upper part depending on the absence or presence of headstones. Neither model collapsed, with only slight headstone displacement occurring at the $0.5 \mathrm{~g}$ level of strong motion. The movement of headstone members was similar to that reported after the actual Gyeongju Earthquake. A similar tendency was demonstrated when the model was exposed to Gyeongju Earthquake motion with a higher proportion of high-frequency components, and considerable differences were observed in the amplification characteristics of the upper part depending on the absence or presence of headstones.

During the dismantling of the models upon the completion of testing, a stone beam in the 19th layer was found to be broken in the centre, as shown in Figure 7. This proves that the stone beams play an important role in enhancing seismic performance by functioning as tie bars. 


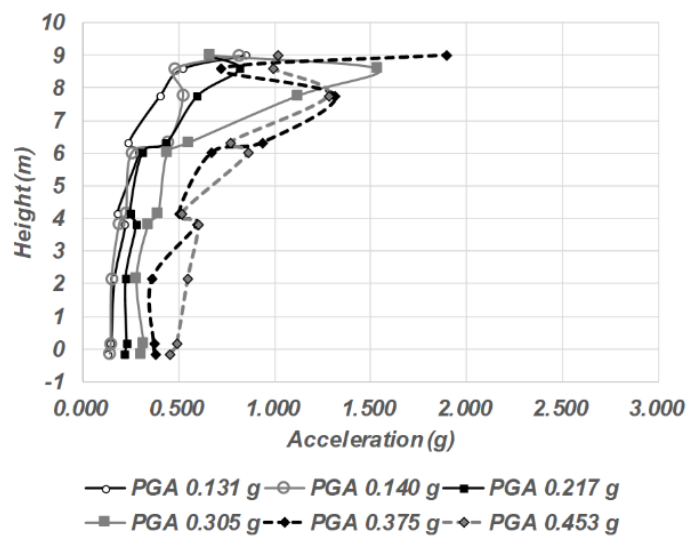

(a)

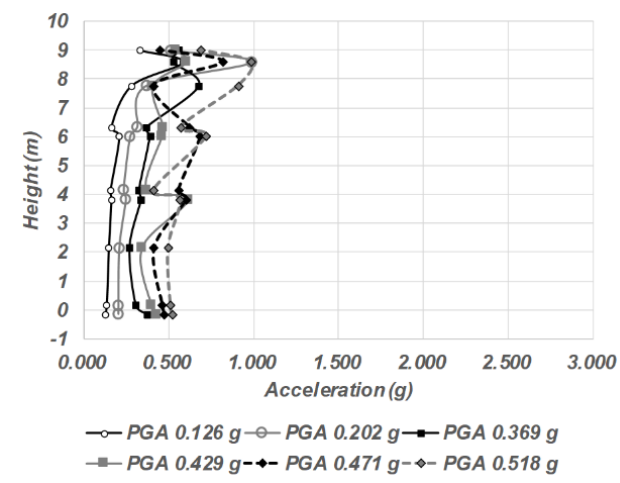

(c)

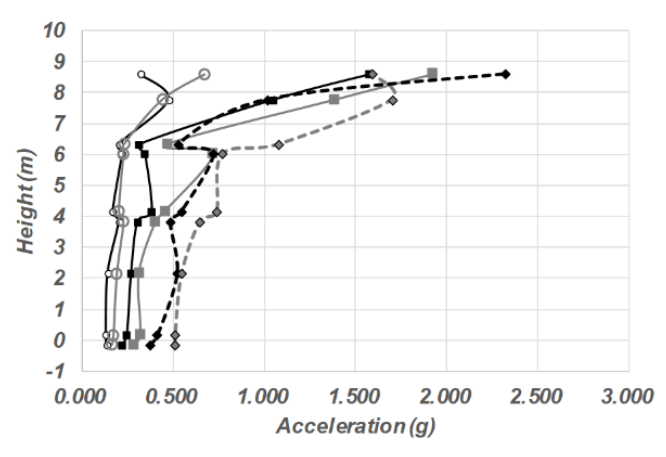

$\multimap$ PGA $0.135 \mathrm{~g}-\mathrm{-}-\mathrm{PGA} 0.165 \mathrm{~g} \rightarrow-P G A 0.219 \mathrm{~g}$

$--P G A 0.284 \mathrm{~g}-\bullet-P G A 0.370 \mathrm{~g}-\diamond-P G A 0.507 \mathrm{~g}$

(b)

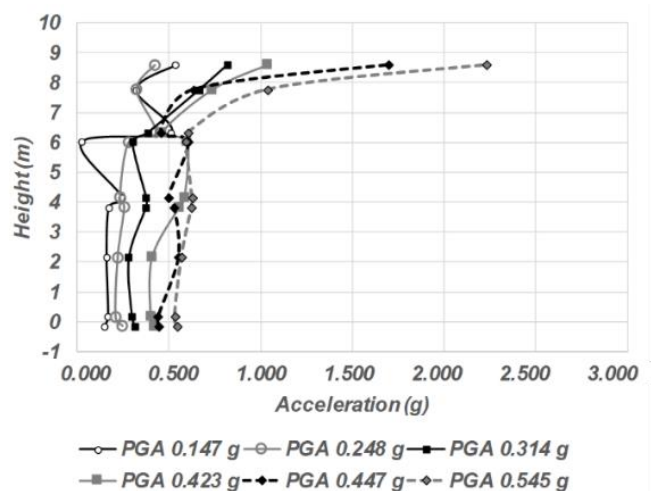

(d)

Figure 6. Peak acceleration values measured at various heights in the two Cheomseongdae models: (a) Ofunato earthquake motion in original model; (b) Ofunato earthquake motion in Cheomseongdae model without headstones; (c) Gyeongju Earthquake motion in original model; and (d) Gyeongju Earthquake motion in Cheomseongdae model without headstones.

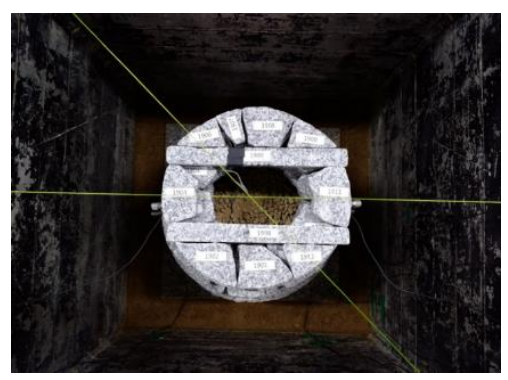

(a)

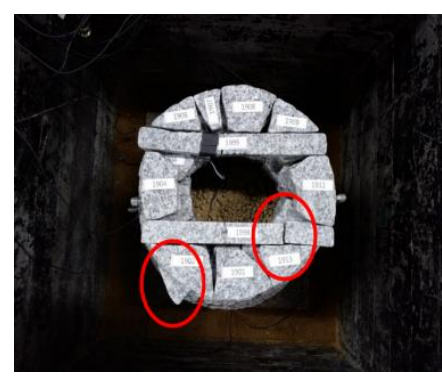

(b)

Figure 7. Broken stone beam of 19th layer after seismic excitations: (a) Before testing; and (b) After testing.

\subsection{Frequency Response of Structure During Earthquake Excitation}

Figure 8 shows the frequency response of the structure exposed to the Ofunato earthquake motion with a $0.137 \mathrm{~g}$-level surface peak acceleration. A peak acceleration of $0.660 \mathrm{~g}$ was measured at the upper headstone (29th layer), and partial amplification occurred in the $2.4-3.9 \mathrm{~Hz}$ and $5.1-6.3 \mathrm{~Hz}$ bands. The amplification profile was not clearly discernible. This may be due to the complex mode 
shape of the structure, which was composed of nearly 400 members. Figure 9 shows the frequency response of the structure exposed to the Gyeongju Earthquake motion with a $0.126 \mathrm{~g}$-level surface peak acceleration. A peak acceleration of $0.329 \mathrm{~g}$ occurred at the topmost layer, and partial amplification occurred at 2.7 and $4.9 \mathrm{~Hz}$.
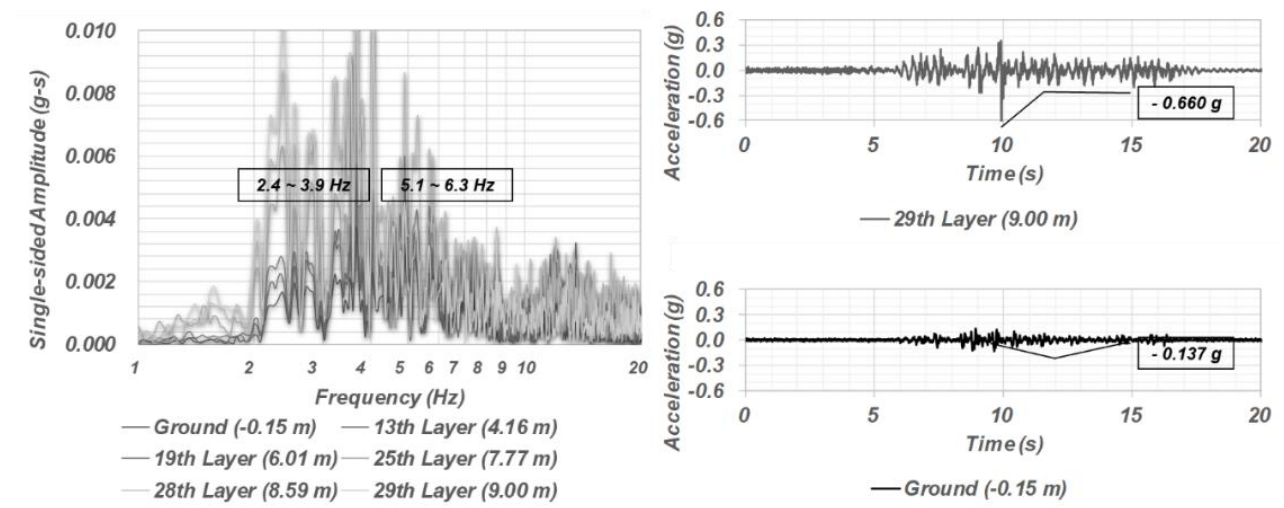

Figure 8. Frequency response of structure exposed to Ofunato earthquake motion.
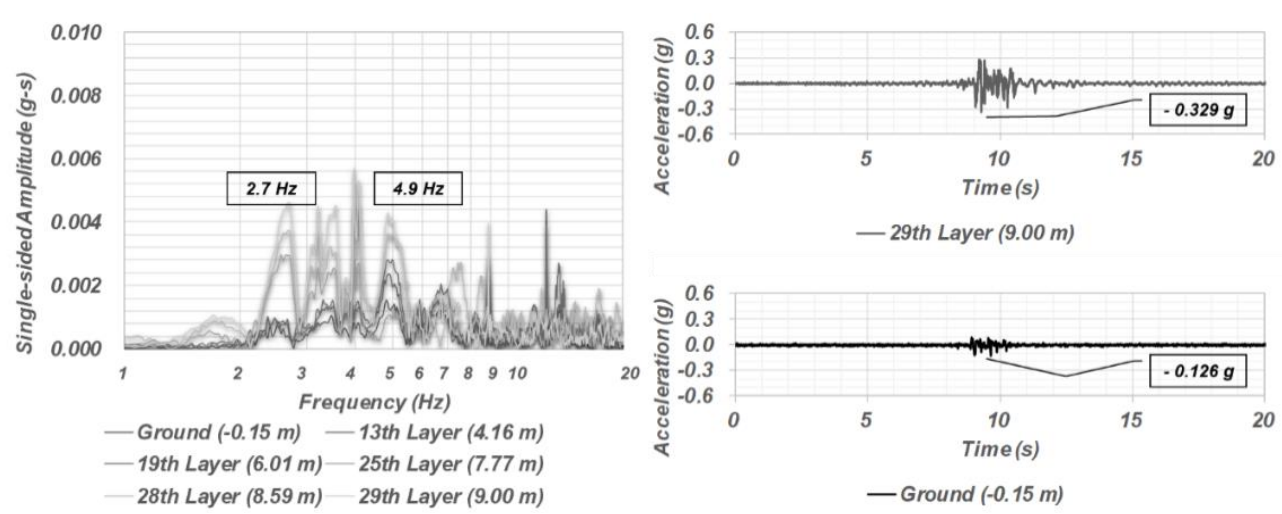

Figure 9. Frequency response of structure exposed to Gyeongju Earthquake motion.

It is difficult to determine the natural frequency of Cheomseongdae, which has almost 400 members [21]. In the Cheomseongdae prototype, acceleration amplification was measured in the $3.23 \mathrm{~Hz}$ and $7.1-11.07 \mathrm{~Hz}$ bands under excitation in the east-west direction. From the test results, it was concluded that Cheomseongdae has a high seismic performance with a harmony between the local behaviour of each member and the overall behaviour of the structure. Additionally, the behaviour of the lower part under the window level packed with filler materials exhibited rigid motion, and the intersecting long beams and interlocking headstones were found to enhance the seismic performance of the upper part with a large empty space.

\section{Conclusions}

This paper summarised and categorised studies conducted between 2009 and 2012 on the seismic risk assessment of architectural heritage in Korea's historic areas in relation to the evaluation of the engineering characteristics of architectural heritage sites, the site-specific ground response analysis for earthquake scenarios, the GIS-based seismic microzonation according to geotechnical earthquake engineering parameters, the reliability assessment of the dynamic centrifuge model testing of stone masonry structure and the seismic performance of architectural heritage. The M 5.8 earthquake that hit Gyeongju on 12 September 2016 was analysed from an engineering point of view and the related damages to stone architectural heritage were categorised according to the type of damage. The reliability and importance of the research achievements presented in this study were highlighted in the Cheomseongdae damage report written after the 2016 Gyeongju Earthquake. The reliability of the 
seismic performance assessment method for architectural heritage based on dynamic centrifuge model testing was also proven using a Gyeongju Earthquake records that have rarely been used in Korea thus far.

The findings of the dynamic centrifuge tests for the Cheomseongdae models using actual Gyeongju Earthquake motion were (1) the different acceleration values with height in the upper part depending on the absence or presence of headstones; (2) the observation of movement of headstone members similar to that reported after the actual 2016 Gyeongju Earthquake; and (3) a broken stone beam in the 19th layer during dynamic centrifuge tests. These findings show that it is not a coincidence that Cheomseongdae, a masonry structure composed of nearly 400 stone members, survived numerous seismic events for over 1300 years. The structural characteristics of Cheomseongdae, such as the well-compacted filler materials in its lower part, the rough inside wall in contrast to the smooth exterior, intersecting stone beams and interlocking headstones, were shown to contribute to its overall seismic performance based on the results of dynamic centrifuge model testing. It is interesting that Cheomseongdae maintained its original form given the ground conditions since the seventh century. It is a great cultural heritage in which we can still feel our ancestors' breaths and rediscover their outstanding seismic design technology.

Author Contributions: Conceptualization, H.-J.P. and J.-G.H.; Formal analysis, J.-G.H.; Funding acquisition, H.-J.P.; Investigation, S.-H.K.; Methodology, H.-J.P., S.-H.K. and S.-S.J.; Resources, S.-H.K. and S.-S.J.; Software, J.-G.H.; Supervision, H.-J.P.; Validation, S.-S.J.; Writing—original draft, H.-J.P.; Writing—review \& editing, H.-J.P.

Funding: This research was also supported by the Basic Science Research Program through the National Research Foundation of Korea (NRF) funded by the Ministry of Education (grant number NRF-2014R1A6A3A04056405).

Acknowledgments: This study, which forms a part of the project, has been achieved with the support of national R\&D project, which has been hosted by National Research Institute of Cultural Heritage of Cultural Heritage Administration. The authors would like to thank Kyung-Sik Seo, Sung-Bok Lee, Tae-Sic Oh, Moon-Gyo Lee, Yeong-Hoon Jeong, Kil-Wan Ko, Hye-Lim Lee, and Sunji Park for their advice and support for centrifuge model tests.

Conflicts of Interest: The authors declare no conflict of interest.

\section{References}

1. Calabresi, G. 1st Kerisel lecture: The role of Geotechnical Engineers in saving monuments and historic sites. In Proceedings of the 18th International Conference on Soil Mechanics and Geotechnical Engineering, Paris, France, 2-6 September 2013; pp. 71-83.

2. Viggiani, C. 2nd Kerisel lecture: Geotechnics and Heritage. In Proceedings of the 19th International Conference on Soil Mechanics and Geotechnical Engineering, Seoul, Korea, 17-22 September 2017; pp. 119-140.

3. Cid, J.; Susagna, T.; Goula, X.; Chavarria, L.; Figueras, S.; Fleta, J.; Casas, A.; Roca, A. Seismic zonation of Barcelona based on numerical simulation of site effects. Pure Appl. Geophys. 2001, 158, 2559-2577. [CrossRef]

4. Gizzi, F.T. Identifying geological and geotechnical influences that threaten historical sites: A method to evaluate the usefulness of data already available. J. Cult. Herit. 2008, 9, 302-310. [CrossRef]

5. Glatron, S.; Beck, E. Evaluation of socio-spatial vulnerability of citydwellers and analysis of risk perception: Industrial and seismic risks in Mulhouse. Nat. Hazards Earth Syst. Sci. 2008, 8, 1029-1040. [CrossRef]

6. Salamon, A.; Katz, O.; Crouvi, O. Zones of required investigation for earthquake-related hazards in Jerusalem. Nat. Hazards 2010, 53, 375-406. [CrossRef]

7. Psycharis, I.N.; Lemos, J.V.; Papastamatiou, D.Y.; Zambas, C.; Papantonopoulos, C. Numerical study of the seismic behaviour of a part of the Parthenon Pronaos. Earthq. Eng. Struct. Dyn. 2003, 32, $2063-2084$. [CrossRef]

8. Konstantinidis, D.; Makris, N. Seismic response analysis of multidrum classical columns. Earthq. Eng. Struct. Dyn. 2005, 34, 1243-1270. [CrossRef]

9. Kounadis, A.N.; Papadopoulos, G.J.; Cotsovos, D.M. Overturning instability of a two-rigid block system under ground excitation. ZAMM-J. Appl. Math. Mech. 2012, 92, 536-557. [CrossRef] 
10. Aguilar, R.; Marques, R.; Sovero, K.; Martel, C.; Trujillano, F.; Boroschek, R. Investigations on the structural behaviour of archaeological heritage in Peru: From survey to seismic assessment. Eng. Struct. 2015, 95, 94-111. [CrossRef]

11. Maria, B.D. Decision Making Based on Benefit-Costs Analysis: Costs of Preventive Retrofit versus Costs of Repair after Earthquake Hazards. Sustainability 2018, 10, 1537. [CrossRef]

12. Kim, J.K.; Ryu, H. Seismic test of a full-scale model of a five-storey stone pagoda. Earthq. Eng. Struct. Dyn. 2003, 32, 731-750. [CrossRef]

13. Peña, F.; Lourenço, P.B.; Alfredo, C.C. Experimental Dynamic Behavior of Free-Standing Multi-Block Structures Under Seismic Loadings. J. Earthq. Eng. 2008, 12, 953-979. [CrossRef]

14. Santi, M.C.; Vincenzo, S.; Irene, L.; Simona, M.C.P. Fiber-Reinforced Polymer Nets for Strengthening Lava Stone Masonries in Historical Buildings. Sustainability 2016, 8, 394. [CrossRef]

15. Zheng, L.; Zhang, H.R.; Jia, C.G.; Peng, Z.M. Seismic Performance of a New Type of Fabricated Tie-Column. Sustainability 2018, 10, 1716. [CrossRef]

16. National Research Institute of Cultural Heritage (NRICH). Research Planning on the Disaster Mitigation of Architectural Heritage; NRICH: Daejeon, Korea, 2008; p. 282. (In Korean)

17. Park, H.J.; Kim, D.M.; Kim, K.S.; Ahn, H.Y.; Kim, D.S. Noninvasive geotechnical site investigation for stability of Cheomseongdae. J. Cult. Herit. 2012, 13, 98-102. [CrossRef]

18. Park, H.J.; Kim, D.S.; Kim, D.M. Seismic risk assessment of architectural heritages in Gyeongju considering local site effects. Nat. Hazards Earth Syst. Sci. 2013, 13, 251-262. [CrossRef]

19. Park, H.J.; Kim, D.S. Centrifuge modelling for evaluation of seismic behaviour of stone masonry structure. Soil Dyn. Earthq. Eng. 2013, 53, 187-195. [CrossRef]

20. Park, H.J.; Kim, D.S.; Choo, Y.W. Evaluation of the seismic response of stone pagodas using centrifuge model tests. Bull. Earthq. Eng. 2014, 12, 2583-2606. [CrossRef]

21. Park, H.J.; Kim, D.S. Evaluation of seismic behaviour of Cheomseongdae using dynamic centrifuge model test. Earthq. Eng. Struct. Dyn. 2015, 44, 695-711. [CrossRef]

22. Ministry of Public Safety and Security. 9.12 Earthquake Whitepaper; Ministry of Public Safety and Security: Sejong, Korea, 2017; 406p. (In Korean)

23. Kim, N.; Hong, S.G.; Koo, I.Y. Study on seismic evaluation for stone heritage pagodas. In Proceedings of the Earthquake Engineering Society of Korea (EESK) Conference, Incheon, Korea, 23 March 2018; pp. 143-144.

24. Yu, H.R.; Park, C. A study on the damaged architectural heritage-Cheomseongdae Observatory-in Gyeongju's from an earthquake. J. Soc. Cult. Herit. Disaster Prev. 2016, 1, 83-89. (In Korean)

25. Jo, S.S.; Kim, D.M.; Kim, D.S. Study on Stone Cultural Heritage's Structural Stability Management-with a Focus on Cheomseongdae. In Structural Analysis of Historical Constructions; Aguilar, R., Torrealva, D., Moreira, S., Pando, M.A., Ramos, L.F., Eds.; RILEM Bookseries; Springer: Basel, Switzerland, 2019; Volume 18, pp. 652-660.

26. Lee, C.H.L.; Park, J.H.; Kim, T.; Kim, S.Y.; Kim, D.K. Damage potential analysis and earthquake engineering-related implications of Sep.12, 2016 M5.8 Gyeongju Earthquake. J. Earthq. Eng. Soc. Korea 2016, 20, 527-536. [CrossRef]

27. Arias, A. A measure of earthquake intensity. In Seismic Design for Nuclear Power Plants; Hansen, R.J., Ed.; MIT Press: Cambridge, MA, USA, 1970; pp. 438-483.

28. Kim, D.S.; Kim, N.R.; Choo, Y.W.; Cho, G.C. A newly developed state-of-the-art geotechnical centrifuge in Korea. KSCE J. Civ. Eng. 2013, 17, 77-84. [CrossRef]

29. Park, H.J.; Ha, J.G.; Kwon, S.Y.; Lee, M.G.; Kim, D.S. Investigation of the dynamic behaviour of a storage tank with different foundation types focusing on the soil-foundation-structure interactions using centrifuge model tests. Earthq. Eng. Struct. Dyn. 2017, 46, 2301-2316. [CrossRef]

(C) 2019 by the authors. Licensee MDPI, Basel, Switzerland. This article is an open access article distributed under the terms and conditions of the Creative Commons Attribution (CC BY) license (http://creativecommons.org/licenses/by/4.0/). 